Supporting Information

\title{
Mesoporous Palladium-Boron-Sulfur Alloy Nanospheres for Efficient Hydrogen Evolution
}

Xuwen Guo, ${ }^{\mathrm{a},+}$ Zhichao Chen,,${ }^{\mathrm{b}+}$ Y Yanping Huang,,${ }^{\mathrm{c}, *}$ Hao Lv, ${ }^{\mathrm{d}}$ Yaru Wang, ${ }^{\mathrm{a}}$ Lizhi Sun, ${ }^{\text {a Kai Song, }}{ }^{\mathrm{e}, *}$ and Ben $\operatorname{Liu}^{\mathrm{a}, \mathrm{d}, *}$

aJiangsu Key Laboratory of New Power Batteries, Jiangsu Collaborative Innovation Center of Biomedical Functional Materials, School of Chemistry and Materials Science, Nanjing Normal University, Nanjing 210023, China.*Email: ben.liu@njnu.edu.cn

bShenzhen RELX Technology Co., Ltd, Shenzhen, 518108 China.

${ }^{c}$ Center of Engineering Experimental Teaching, School of Chemical Engineering, Sichuan University, Chengdu 610065, China. Email: huangyp_scu@126.com

${ }^{\mathrm{d} C o l l e g e ~ o f ~ C h e m i s t r y, ~ S i c h u a n ~ U n i v e r s i t y, ~ C h e n g d u ~ 610064, ~ C h i n a . ~}$

eSchool of Life Science, Changchun Normal University, Changchun 130032, China. *Email: songkai@ccsfu.edu.cn

${ }^{+} \mathrm{X}$. Guo and Z. Chen contribute equally to this work. 


\section{Chemicals and Materials}

Palladium(II) chloride $\left(\mathrm{PdCl}_{2}, 99.9\right.$ wt. \%), ammonium fluoride $\left(\mathrm{NH}_{4} \mathrm{~F}\right)$, boric acid $\left(\mathrm{H}_{3} \mathrm{BO}_{3}\right)$, borane dimethylamine complex (DMAB), sodium hypophosphite $\left(\mathrm{NaH}_{2} \mathrm{PO}_{2}\right)$, sodium hyposulfite $\left(\mathrm{Na}_{2} \mathrm{~S}_{2} \mathrm{O}_{3}\right)$, octadecyl trimethyl ammonium chloride $\left(\mathrm{C}_{18} \mathrm{TAC}\right)$, behenyl trimethyl ammonium chloride $\left(\mathrm{C}_{22} \mathrm{TAC}\right)$, dioctadecyldimethylammonium chloride (DODAC), didodecyldimethylammonium chloride, dioctyldimethylammonium chloride, ascorbic acid (AA), and acetic acid were obtained from Alfa Aesar. Nafion solution and commercial Pd/C were obtained from Sigma-Aldrich. Hydrochloric acid $(\mathrm{HCl})$, ammonia solution $\left(\mathrm{NH}_{3} \cdot \mathrm{H}_{2} \mathrm{O}\right)$, and sodium hydroxide $(\mathrm{NaOH})$ were purchased from Sinopharm Chemical Reagent Co. Ltd. (Shanghai). Behenyl trimethyl ammonium chloride $\left(\mathrm{C}_{22}\right.$ TAC) was synthesized according to our previously reported work (Chem. Sci. 2018, 9, 4451). To prepare 10 $\mathrm{mM} \mathrm{H}_{2} \mathrm{PdCl}_{4}$ solution, $0.355 \mathrm{~g}$ of $\mathrm{PdCl}_{2}$ was first dissolved into $20 \mathrm{~mL}$ of $0.20 \mathrm{M} \mathrm{HCl}$ solution, and then diluted with $180 \mathrm{~mL}$ of deionized $\mathrm{H}_{2} \mathrm{O}$. Deionized $\mathrm{H}_{2} \mathrm{O}$ with the resistivity of $18.25 \mathrm{~m} \Omega$ was used in all experiments.

\section{Synthesis of ternary PdBS alloy mesoporous nanospheres (MSs)}

Ternary PdBS alloy MSs were synthesized by an aqueous route using $\mathrm{H}_{2} \mathrm{PdCl}_{4}$ as the metal precursor, DODAC as the surfactant template, $\mathrm{Na}_{2} \mathrm{~S}_{2} \mathrm{O}_{3}$ as the $\mathrm{S}$ source, and DMAB as the B sources at $95{ }^{\circ} \mathrm{C}$, respectively. $\mathrm{Na}_{2} \mathrm{~S}_{2} \mathrm{O}_{3}$ and $\mathrm{DMAB}$ were also used as the co-reducing agents to drive the crystalline nucleation and growth of the PdBS alloys. In a typical synthesis, $15.0 \mathrm{mg}$ of DODAC was totally dissolved in $5.0 \mathrm{~mL}$ of deionized $\mathrm{H}_{2} \mathrm{O}$ to obtain a homogeneous solution, followed by the addition of $0.50 \mathrm{~mL}$ of $0.337 \mathrm{M} \mathrm{NH}_{4} \mathrm{~F}$ solution, $0.50 \mathrm{~mL}$ of $0.101 \mathrm{M} \mathrm{H}_{3} \mathrm{BO}_{3}$ solution, and $0.40 \mathrm{~mL}$ of $10 \mathrm{mM} \mathrm{H}_{2} \mathrm{PdCl}_{4}$ solution. After incubated for $5 \mathrm{~min}, 0.20 \mathrm{~mL}$ of $\mathrm{NH}_{3 \square} \cdot \mathrm{H}_{2} \mathrm{O}(2.5-2.8 \mathrm{wt}$. \%) was injected to adjust the $\mathrm{pH}$ of the solution. The color of the solution was changed from pink to colorless correspondingly. Then, $0.50 \mathrm{~mL}$ of $1.0 \mathrm{mg} / \mathrm{mL} \mathrm{Na}_{2} \mathrm{~S}_{2} \mathrm{O}_{3}$ was added into the above solution, and further incubated at $95{ }^{\circ} \mathrm{C}$ for $30 \mathrm{~min}$. Lastly, $0.50 \mathrm{~mL}$ of freshly prepared $0.10 \mathrm{M} \mathrm{DMAB}$ was injected to start the reduction. In this stage, the color of the solution was gradually evolved into dark brown. After kept at $95{ }^{\circ} \mathrm{C}$ for 120 min, the product was collected by centrifuged and washed several times with ethanol/ $\mathrm{H}_{2} \mathrm{O}$. Besides, reaction temperatures, $\mathrm{H}_{2} \mathrm{PdCl}_{4}$ amounts, $\mathrm{Na}_{2} \mathrm{~S}_{2} \mathrm{O}_{3}$ amounts, and surfactant species were also tuned to tailor the nanostructures of as-resulted PdBP alloys under the similar procedures.

Binary PdB alloy MSs were synthesized using the similar procedures, but only using DMAB as the B source and reducing agent solely at $75{ }^{\circ} \mathrm{C}$ (without $\mathrm{Na}_{2} \mathrm{~S}_{2} \mathrm{O}_{3}$ ), while monometallic Pd MSs were obtained using ascorbic acid as the reducing agent (see Chem. Sci. 2019, 10, 1986 for more synthetic details).

Quaternary PdCuBS MSs were obtained with the same procedures to PdBS alloy MSs but using $\mathrm{H}_{2} \mathrm{PdCl}_{4}$ and $\mathrm{Cu}\left(\mathrm{NO}_{3}\right)_{2}$ as the metal precursors.

Monometallic Pd MSs were synthesized with DODAC as the surfactant template and ascorbic acid as reducing agent as previous report (Chem. Sci. 2019,10, 1986). 


\section{Electrochemical hydrogen evolution reaction (HER) measurements}

Electrochemical HER was carried out using a three-electrode system at $25^{\circ} \mathrm{C}$, where glass carbon electrode (GCE, $0.07065 \mathrm{~cm}^{2}$ ) connected to an $\mathrm{CHI} 660 \mathrm{E}$, carbon rod, and $\mathrm{Ag} / \mathrm{AgCl}$ electrode were used as the electrochemical workstation, the counter electrode, and the reference electrode, respectively. To prepare an ink of the naocatalysts, $1.0 \mathrm{mg}$ of the nanocatalysts and $2.0 \mathrm{mg}$ of Vulcan XC-72 carbon were added to $0.80 \mathrm{~mL}$ of ethanol and $0.20 \mathrm{~mL}$ of $\mathrm{H}_{2} \mathrm{O}$, and further mixed by sonicating for $0.5 \mathrm{~h}$. Subsequently, $50 \mu \mathrm{L}$ of Nafion solution $(5 \mathrm{wt} \%$ in alcohol and $\mathrm{H}_{2} \mathrm{O}$ ) was added and sonicated for another $0.5 \mathrm{~h}$. Then, $6.0 \mu \mathrm{L}$ of above-prepared ink solution was dropped on the GCE electrode and dried at room temperature before the test. All the HER tests were carried out in $\mathrm{N}_{2}$-saturated 0.5 $\mathrm{M} \mathrm{H}_{2} \mathrm{SO}_{4}$ at $25^{\circ} \mathrm{C}$. $\mathrm{I}_{\mathrm{r}}$ compensation and background current correction were applied to the HER LSV measurements for all the nanocatalysts.

The TOF value can be calculated according to the following equation:

$$
\text { TOF }\left(s^{-1}\right)=\frac{I}{2 F_{\mathrm{n}}}
$$

where $I$ is the current (A) during LSV test, $F$ is the Faraday constant $\left(96485 \mathrm{C} \mathrm{mol}^{-1}\right), n$ is the number of active sites (mol) obtained by the under potential deposition (UPD) method.

\section{Characterizations}

TEM and high-resolution TEM studies were carried out using a JEOL 2010 TEM with an accelerating voltage of $200 \mathrm{kV}$. HAADF-STEM was performed on FEI Talos F200X apparatuses at an accelerating voltage of $200 \mathrm{kV}$, which are equipped with STEM and EDS detectors for elemental mapping analysis. TEM and STEM samples were prepared by casting a suspension of the samples (in ethanol and/or $\mathrm{H}_{2} \mathrm{O}$ ) on a carbon coated copper grid (300 mesh). XRD patterns were collected on the powder samples using a D/max $2500 \mathrm{VL} / \mathrm{PC}$ diffractometer (Japan) equipped with graphite-monochromatized $\mathrm{Cu} \mathrm{K} \alpha$ radiation. XPS was performed on a scanning X-ray microprobe (Thermo ESCALAB 250Xi) that uses Al K $\alpha$ radiation. The binding energy of the $\mathrm{C} 1 \mathrm{~s}$ peak $(284.8 \mathrm{eV})$ was employed as a standard to calibrate the binding energies of other elements. ICP-MS was recorded on a NexION 350D. 


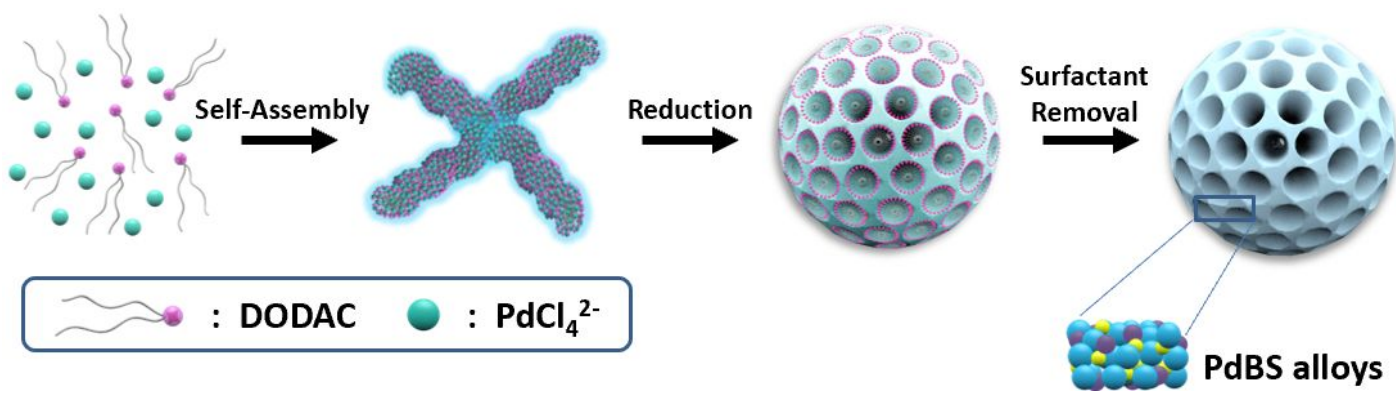

Figure S1. A scheme illustrating the surfactant-templating synthesis of ternary PdBS alloy MSs through liquidcrystal template self-assembly approach.

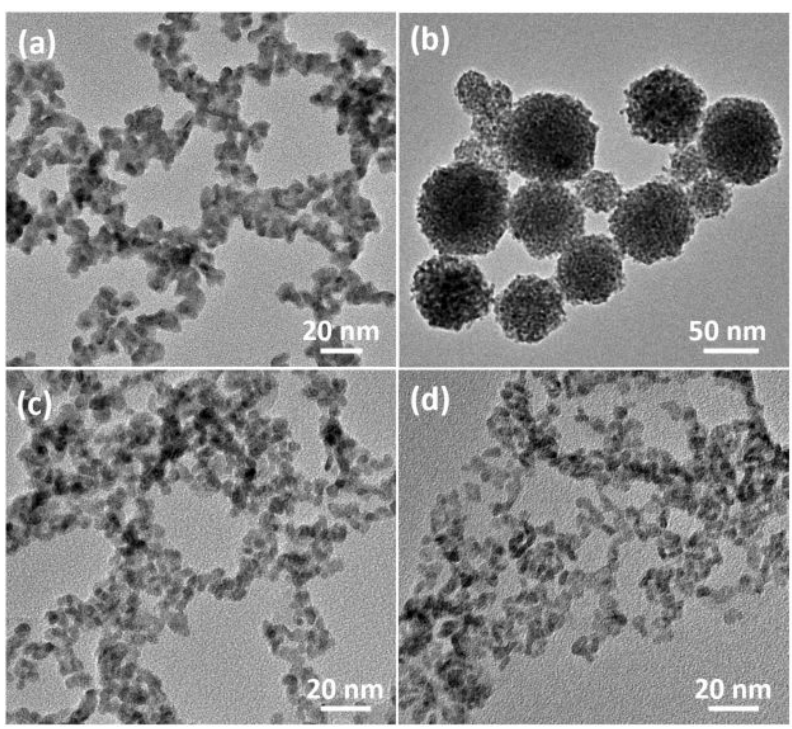

Figure S2. TEM images of ternary PdBS alloys synthesized with different surfactant templates of (a) dioctyldimethylammonium chloride, (b) didodecyldimethylammonium chloride, (c) octadecyl trimethyl ammonium chloride $\left(\mathrm{C}_{18} \mathrm{TAC}\right)$, and $(\mathrm{d})$ behenyl trimethyl ammonium chloride $\left(\mathrm{C}_{22} \mathrm{TAC}\right)$.

Notes for Figure S3: When the surfactants with the same chemical structure but shorter hydrophilic tails were used as the templates, we found that dioctyldimethylammonium chloride $\left(\mathrm{C}_{8}\right.$ tails $)$ only templated the synthesis of nanoparticle aggregates, indicating in situ nucleation of PdBS alloys disrupted the surfactant mesophases (Fig. S2a). Didodecyldimethylammonium chloride $\left(\mathrm{C}_{12}\right.$ tails $)$, however, oriented the formation of PdBS alloy MSs with wormlike pore architectures (Fig. S2b). It is possibly because of the changed assembled structures based on different packing parameters (ACS Nano 2019, 13, 12052; Chem. Rev. 2007, 107, 2821). By sharp comparison, in the presence of the surfactants with one hydrophilic tail, the resultant products were only nanoparticles and their aggregates, indicating the disability to drive the confinement nucleation of PdBS MSs along the templates (Figs. S2c and S2d). 

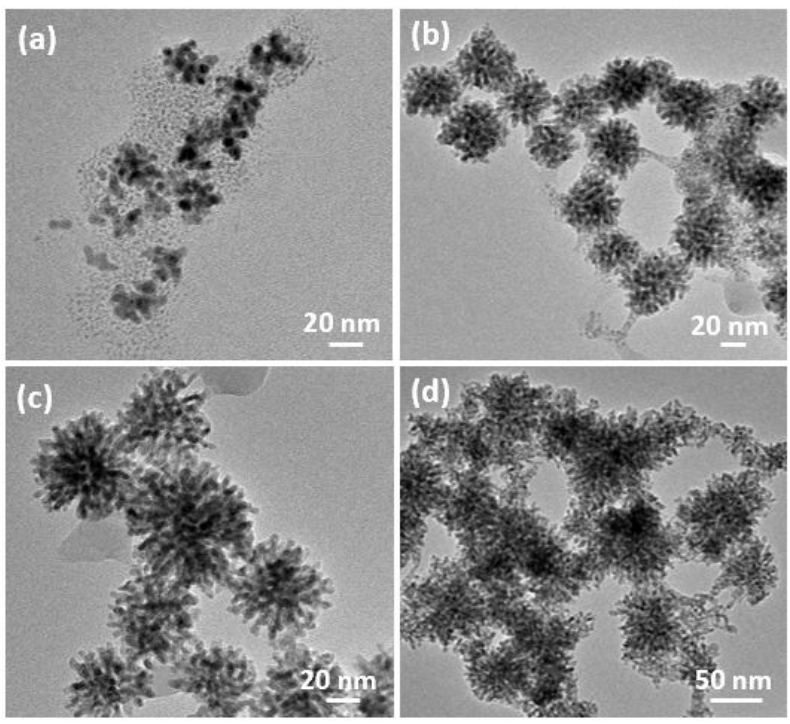

Figure S3. TEM images of ternary PdBS alloy MSs synthesized under different $\mathrm{PdCl}_{4}{ }^{2-}$ amounts (10 mM) of (a) $0.05 \mathrm{~mL}$, (b) $0.2 \mathrm{~mL}$, (c) $0.8 \mathrm{~mL}$, and (d) $1.6 \mathrm{~mL}$.
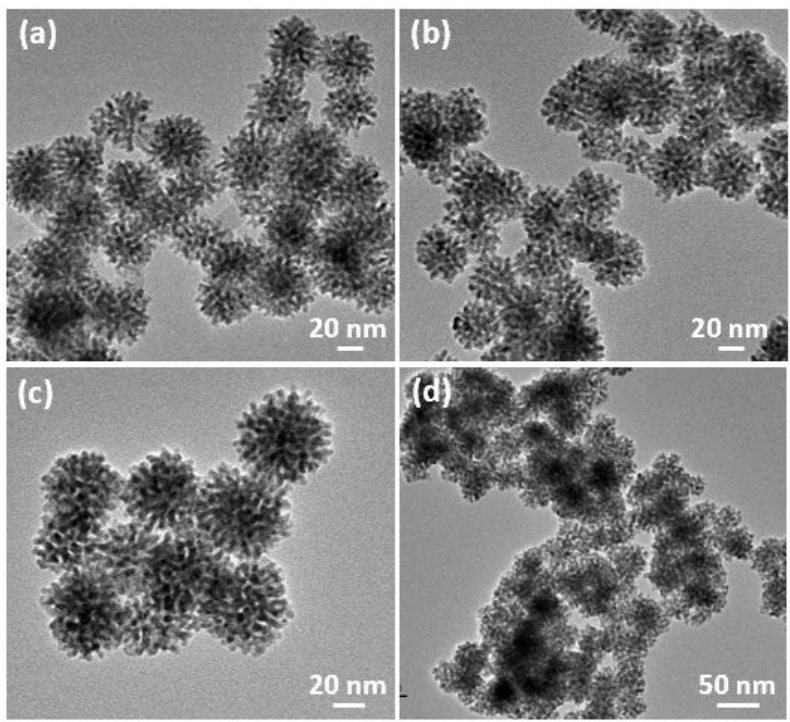

Figure S4. TEM images of ternary PdBS alloy MSs synthesized under different reaction temperatures of (a) $50{ }^{\circ} \mathrm{C}$, (b) $75^{\circ} \mathrm{C}$, (c) $95^{\circ} \mathrm{C}$, and (d) $110^{\circ} \mathrm{C}$.

Notes for Figures $\mathbf{S 3}$ and S4: When changing the $\mathrm{PdCl}_{4}{ }^{2-}$ amounts in the fixed DODAC concentration, the nucleation growth along surfactant templates was correspondingly changed (Figure S3). We found, only under optimal amount $\left(0.4 \mathrm{~mL}\right.$ of $\left.10 \mathrm{mM} \mathrm{PdCl}_{4}^{2-}\right)$, perfect PdBS alloy MSs with 3D central-radial pore architectures were obtained. Under the lower amounts, PdBS alloy MSs with smaller sizes and opened channels were obtained. 
Differently, under the higher amounts, the resultant PdBS alloy MSs were thicker mesoporous frameworks and disordered structures. Similarly, the synthesis temperatures also affected the structures (Figure S4). Under a temperature lower than $95{ }^{\circ} \mathrm{C}$, the products were central-radial MSs. In these conditions, the lower temperatures slightly decreased the diameters of PdBS MSs, which was originated from different reduction rates. However, the high synthesis temperature $\left(110^{\circ} \mathrm{C}\right)$ partially destroyed mesoporous structures.

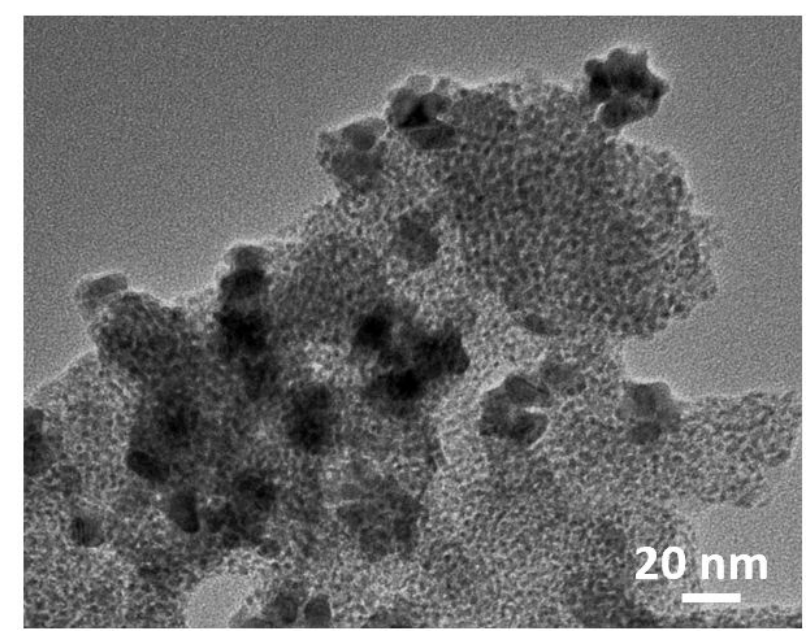

Figure S5. TEM image of ternary PdBS alloys with S ratios of 38 at. \%.

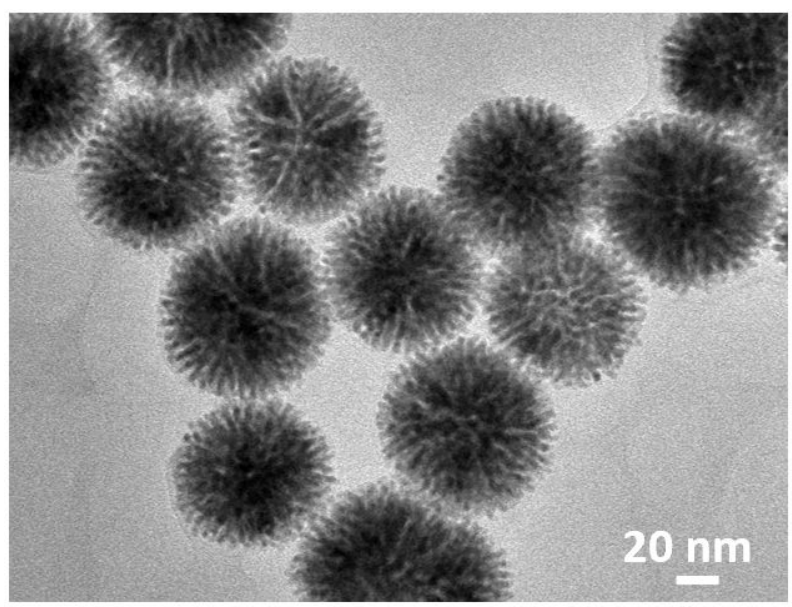

Figure S6. TEM image of monometallic Pd MSs. 


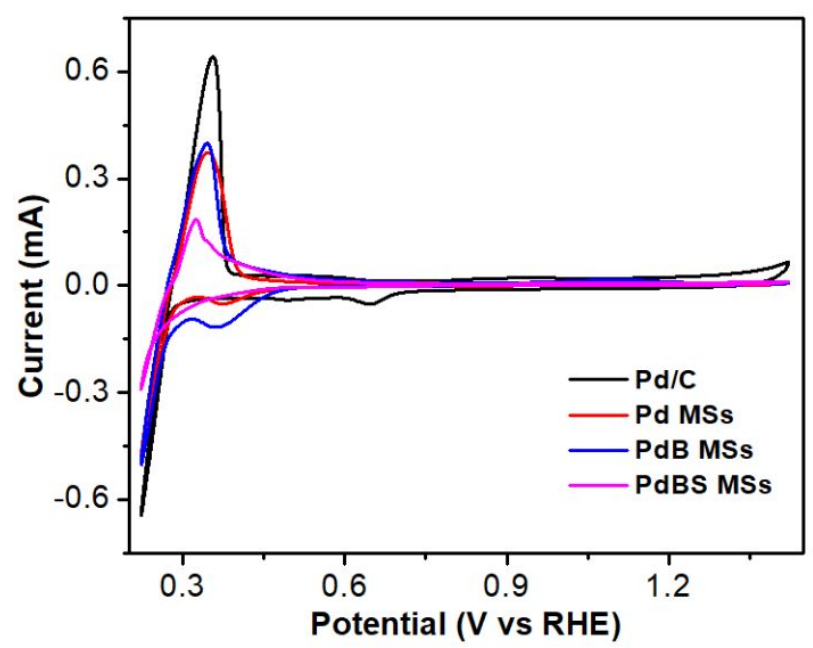

Figure S7. CV curves of $\mathrm{Pd} / \mathrm{C}, \mathrm{Pd} \mathrm{MSs}, \mathrm{PdB} \mathrm{MSs}$, and PdBS MSs collected in $0.05 \mathrm{M} \mathrm{H}_{2} \mathrm{SO}_{4}$ and $0.05 \mathrm{M}$ $\mathrm{CuSO}_{4}$ with a scan rate of $10 \mathrm{mV} \mathrm{s}^{-1}$.

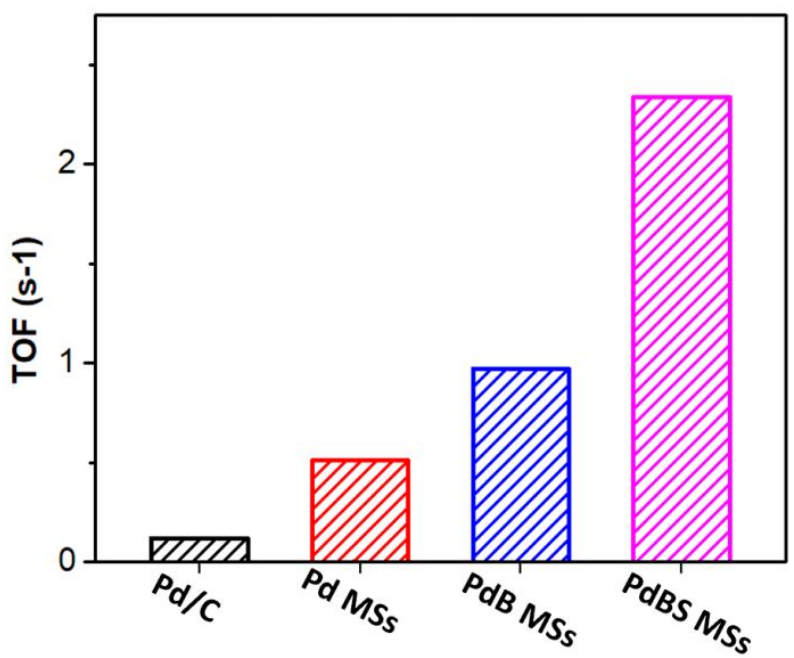

Figure S8. Summarized TOF values of Pd/C, Pd MSs, PdB MSs, and PdBS MSs collected in the overpotential of $75 \mathrm{mV}$. 